\title{
NOVALIS: FILOSOFIA E POÉTICA DA MEDICINA*
}

\author{
Fabiano Lemos** \\ https://orcid.org/0000-0003-3837-9776 \\ fabianolemos@gmail.com
}

RESUMO O artigo analisa a importância das reflexões sobre medicina, a dinâmica do corpo, da doença e da saúde, tais como desenvolvidas pelo médico John Brown no século XVIII, sobre a filosofia da natureza de Novalis, contextualizando a recepção dessas reflexões do âmbito romântico-idealista da Alemanha do começo do século XIX.

Palavras-chave Novalis, John Brown, filosofia da medicina, filosofia da natureza.

ABSTRACT This paper examines the relevance for Novalis's philosophy of nature of John Brown's reflections upon Medicine, dynamics of body, illness and health, the way they were developed by this $18^{\text {th }}$ century physician, by setting the context for it within the romantic-idealist Germany of the early $19^{\text {th }}$ century.

Keywords Novalis, John Brown, philosophy of Medicine, philosophy of nature.

Sollen Körper und Seele viellecht auf gewisse Weise getrennt seyn $[\ldots]$ ? (Novalis)

Je ne suis pas mort, mais je suis separé. (Artaud)

* Artigo submetido em 19/02/2018 e aprovado em 10/04/2018. CNPQ.

** Universidade do Estado do Rio de Janeiro - UERJ. Rio de Janeiro, RJ, Brasil.

KRITERION, Belo Horizonte, nº 142, Abr./2019, p. 65-84 


\section{I.}

Em 1802, cerca de quatrocentos estudantes de medicina da universidade de Göttingen enfrentaram-se enfurecidamente pelas ruas da cidade em um conflito que se estendeu por dois dias e só pôde ser disperso com a intervenção das forças armadas locais. Embates entre estudantes não eram exatamente uma novidade - nem uma exceção - na Alemanha a essa altura, e, ao longo do século XIX, foram mesmo gradualmente se institucionalizando, ainda que não oficialmente, sob a forma dos duelos com que os calouros universitários atestavam a passagem para a vida em sociedade. O evento de Göttingen, contudo, não pertence a essa dinastia: a querela entre os estudantes havia se estabelecido não por uma questão de honra ou pelo mero ímpeto juvenil - ela se dava em torno de uma teoria, entre os defensores (cada vez mais numerosos) e os detratores (cada vez mais furiosos) da doutrina médica de John Brown. ${ }^{1}$

Relativamente ignorado no mundo anglófono, o médico escocês John Brown (1735-1788) teve, na passagem do século XVIII para o XIX, uma surpreendente penetração na paisagem intelectual alemã. Em 1780, Brown havia publicado em Edimburgo um tratado escrito em latim intitulado Elementa Medicinae - traduzido para o inglês pelo próprio autor alguns anos depois -, onde se formulava uma teoria dos estímulos fundamentalmente distinta das abordagens clássicas até então. As teorias disponíveis até aquele momento ainda se apoiavam amplamente na hipótese humoral hipocrática (e em sua transformação doutrinária pós-Galeno), que, como é bem conhecido, considerava as doenças como o resultado de problemas específicos da localização de elementos físicos de natureza invariável, os humores - as bílis negra e amarela, a fleuma e o sangue (cf. Longrigg, 1993, pp. 90-91). Mesmo sem conceder totalmente a essa teoria, a patologia alemã do começo do século XVIII ainda considerava as doenças, em geral, como fruto da perturbação do equilíbrio inato do organismo - e, mesmo em 1794, ainda se podia ler em historiadores da medicina, como Kurt Sprengel ou August Hecker, o louvor explícito à figura-chave de Hipócrates (cf. Broman, 1996, p. 141). O livro de Brown desloca-se consideravelmente dessa abordagem. Sua hipótese central era a de que tanto a doença quanto a saúde seriam promovidas por meio da resposta produzida pelo corpo aos inúmeros estímulos - internos e externos - aos quais estaria submetido. Os humores apontam ainda para certas propriedades ontológicas, enquanto em Brown, mesmo uma propriedade 
qualquer do sistema corpóreo, por última e sintetizadora que seja, é definida dinamicamente. As teorias do estímulo clássicas ainda tentavam derivar a capacidade de estimulação das propriedades de partes dos corpos. Em Brown ocorre o contrário. Cada ser vivo teria sido dotado ao nascer, segundo sua teoria, de uma certa quantidade variável daquilo que ali se denominava excitabilidade, ${ }^{2}$ e essa propriedade só poderia ser manifestada, por sua vez, por meio de sua resposta aos estímulos ou potências excitantes [potestates incitantes, na versão latina, exciting powers, na inglesa]. Toda a unidade do sistema orgânico seria conduzida, assim, à hipótese geral de um funcionamento relacional. $\mathrm{O}$ esquema de analogia quantitativa proposto pelo próprio Brown insiste nessa compreensão do fenômeno geral da vida: se imaginarmos que um indivíduo, ao nascer, possui o grau 80 de excitabilidade, e, ao morrer, esse grau se anula, ou seja, é igual a 0 , logo, a soma entre os estímulos e a quantidade de excitabilidade ao longo de sua vida nunca poderá ultrapassar a quantidade inicial (cf. Brown, 1803, p. 99). Desse modo, um estímulo cuja força tivesse grau igual a 20 teria como resposta da propriedade da excitabilidade o grau 60. Ao aproximar-se da morte, o corpo receberia uma quantidade enorme de estímulos, mas reagiria muito pouco a ela - digamos, um nível de forças estimulantes igual a 78, que teria como resultado reativo o grau 2. O desequilíbrio que caracterizaria a doença se daria, assim, quando a distribuição da relação excitabilidade-estímulos não estivesse de acordo com as circunstâncias da vida de um paciente - sua idade, contexto alimentar etc. Com isso, tanto a diminuição mórbida das forças reativas, que os Elementa denominavam astenia (aesthenic diseases), quanto a hipersensibilidade reativa, a estenia (sthenic diseases), poderiam ser explicadas por um único princípio, e, mais ainda, pela atividade unívoca desse princípio, e não por sua deficiência. ${ }^{3}$

A noção de equilíbrio orgânico em Brown não comporta nenhuma referência a um estado estático primitivo ou, o que é mais significativo no que diz respeito à prática da clínica que ela deriva, permite uma certa redução diagnóstica operacional a uma única matriz de inteligibilidade (algo que encontra sugestivas afinidades com a demanda neoclássica da simplicidade dos princípios explicativos, como em Goethe ou Schiller), ${ }^{4}$ uma vez que nenhum

2 Incitabilitas, na versão original em latim, excitability, na versão para o inglês feita pelo próprio autor. Cf. Brown (1803, p. 89; 1784, p. 4).

3 Brown (1803, p. 112). Cf., também, p. 93: “Uma vez que as potências gerais [general powers] produzem todos os fenômenos da vida, e a única operação, pela qual elas o fazem, é um estimulante, segue-se que todo o fenômeno da vida, todo estado e grau de saúde e doença, são devidos a estímulos e a nenhuma outra causa".

4 Como sugerido, também de passagem, em Broman (1996, p. 141, nota 33). 
desequilíbrio é atribuível a uma parte ou função do corpo em particular, mas resulta de uma economia geral do sistema físico. ${ }^{5}$ Da posição segundo a qual são somente os estímulos produzem o nível de excitabilidade de um corpo, Brown tirou conclusões extremamente influentes entre os leitores alemães da passagem para o século XIX. A principal delas é que o caráter sistêmico e agonístico da ação das forças dentro e fora do corpo acabava por transformálo numa espécie de função tendencial dessas forças, em que a positividade inexorável dessa sua ação seria o paradigma fundamental. A doença não corresponderia a um grau zero da excitabilidade tomada como valor estático, mas a um desequilíbrio entre a quantidade de força exigida pela excitabilidade numa dada ocasião e a capacidade de um estimulante específico. A falta aqui não é um valor absoluto, mas uma espécie de interação entre os níveis variáveis de excitabilidade e estímulo:

Como há sempre alguma excitabilidade, por menor que seja, enquanto a vida permanece, e como a ação das potências excitantes sempre existe em algum grau, concluo que elas [as potências] têm maior ou menor efeito estimulante, e que esse pode ser tanto excessivo, nas devidas proporções, quanto muito pequeno. Uma grande quantidade de sangue estimula em excesso e, portanto, produz as doenças que dependem de muito estímulo, mas uma proporção menor de sangue, apesar de debilitante em seu efeito, e de induzir doenças que dependem da debilidade, ainda deve ser considerada estimulante [...] (Brown, 1803, pp. 90-91).

O "corpo" [corpus, body] surge, nesses termos, não como a entidade ontológica neutra onde forças viriam operar, enfraquecendo-o ou superestimulando-o, mas, antes, como um complexo sistema de interações entre efeitos estimulantes: "Pela palavra corpo se quer dizer tanto o corpo assim simplesmente chamado quanto aquele dotado de uma parte intelectual, uma parte apropriada às paixões e à emoção ou uma alma [soul]: a denominação usual nos escritos médicos é sistema [system]". ${ }^{6}$ Tal centralidade da ação como pressuposto da identidade estava na ordem do dia no contexto da geração que viu na Doutrina da ciência de Fichte uma promessa ainda não realizada nessa direção.

5 Embora Brown admita a existência de doenças locais, por oposição a universais, que afetam todo o sistema, a questão aqui está relacionada ao espectro de ação do desequilíbrio, e não à sua natureza. Cf. Brown (1803, p. 87). O que significa dizer que, na topografia browniana, as causas locais das doenças são modos de uma disposição única: "É somente a excitação [excitment], em seus vários graus, que produz tanto a saúde quanto a doença e a recuperação. Somente ela governa tanto as doenças universais quanto locais: nenhuma delas nunca surge por causa dos sólidos ou fluidos, mas somente pelo aumento ou pela diminuição da excitação" (ibidem, p. 112).

6 Brown (1803, p. 89). A versão latina é ligeiramente mais econômica: "Vocabulo corpus, tam corpus simpliciter dictum quam etiam mente, animo, vel anima, preditum significatur, systema vulgo dictum" (Brown, 1784, p. 4). 
Assim, a medicina em Brown só pode ser sistemática porque é sistêmica. As forças atuantes no organismo mantêm com ele uma relação axiomática invertida em relação ao modelo hipocrático: não são apenas elementos portadores de sentido que circulam em espaços definidos do corpo, constituindo uma topografia qualquer; são, antes, produtoras dos fenômenos que constituem o corpo enquanto tal. Tais forças dão lugar não apenas às deficiências orgânicas, mas permitiriam a emergência mesma do "sentido, do movimento, da operação mental e das paixões" (Brown, 1803, p. 89; 1784, p. 4). Essa generalização do estímulo como fenômeno próprio da vida ia de encontro às práticas clínicas então em vigência, que compreendiam os distúrbios orgânicos do ponto de vista de um excesso imposto a um quantum estático ideal que definia o estado normal e equilibrado da existência corporal. A medicina clássica, portanto, insistia em uma dietética cujos alimentos deveriam ser digeridos sem o menor esforço e tornava a sangria o procedimento geral de cura dos intumescimentos causados pelos excessos estimulantes: ${ }^{7}$ uma cartografia circulatória onde se podia localizar, sem muita dificuldade, os espaços devidos e indevidos, aconselháveis e interditos. A clínica de Brown, ao contrário, ao colocar as doenças e a saúde sob um mesmo domínio de afecções - aquilo que Foucault chamou de monismo patológico (Foucault, 1963, p. 181 ) - não tem por objetivo reconduzir ao estado estático primordial (para ela inexistente), mas procura resolver o desequilíbrio por meio da aquisição de um novo movimento dos corpos, mais adequado a cada tipo de efeito pensamento, paixões etc. - e a cada etapa da vida dos indivíduos. Começa, com isso, a era dos estimulantes no horizonte da cura na medicina - o próprio Brown tendo defendido, aliás, o uso mais liberal de bebidas alcóolicas e do ópio para as indisposições orgânicas (Cf. Brown, 1803, p. 96; Tsouyopoulos, 1988, p. 72; Neubauer, 1967, p. 370) - e, correspondentemente, inaugura-se uma certa mitologia do alcoolismo e do uso de entorpecentes, que vai fazer, por exemplo, da obra de Hoffmann (e, na França, um pouco mais tarde, das de Nerval e Baudelaire) um local paradigmático (cf. Dutchman-Smith, 2009, especialmente pp. 87 e ss.).

O que é particularmente estranho na recepção bem-sucedida dessa teoria na Alemanha é que, apesar de sua elegância heurística, de seu princípio simples e total, o caráter relativamente passivo que ela atribuía à reação interna diante

7 É assim, por exemplo, que Ambroise Paré, cirurgião do rei da França, pode dizer, em meados do século XVI, que: "A quantidade de sangue que se tira [de um doente] se mede em relação à força da virtude e à grandeza da doença" e recomenda que os cirurgiões-barbeiros não tenham temor em sangrar continuamente seus pacientes, desde que observem a estabilidade de sua constituição física (Paré, 1953, p. 125). 
dos estímulos externos, transformando a vida numa aventura na qual o $\mathrm{Eu}$ perde muito do seu controle - e, além disso, na qual tudo parece se dirigir ao esgotamento -, é sensivelmente incompatível com a formulação cada vez mais complexa da ideia de autonomia nos meios intelectuais, de Kant a Schelling. Isso explica por que esse último, em seu texto de 1798, Von der Weltseele, chama a atenção para a armadilha da teoria de Brown: segundo Schelling, ela poderia parecer, a princípio, apresentar a dinâmica entre um elemento positivo (no caso, a excitabilidade) e um outro, negativo (as potências excitantes). No entanto, ele adverte, Brown, por compreender os estímulos como variações não fundadas em uma unidade sintética, ou seja, porque sua fonte não era previsível e controlável, acabaria por converter as forças internas da vida animal em princípios "meramente passivos" (Schelling, 1907, p. 601). Para ele, como para toda a geração idealista pós-kantiana, é a busca pela unidade transcendental que fundamenta a filosofia, as ciências, enfim, o pensamento ontológico. Situada no contexto da variação dinâmica dos estímulos, a propriedade da excitabilidade na teoria médica browniana parece surgir, para Schelling, como efeito, e não como causa dos processos orgânicos, e, portanto, não pode ocupar a função de princípio sistemático-explicativo.

Uma dificuldade semelhante refere-se à grande diferença metodológica entre a teoria de Brown e o problema da fundamentação epistemológica do conhecimento que teve lugar, sobretudo, após a Crítica da razão pura. Pois a recusa insistente dos Elementa de pensar o corpo desde o ponto de vista da estabilidade, em última análise, estava ligada a uma rejeição mais basilar: o que poderíamos denominar como o empirismo radical de Brown -

Não sabemos o que é a excitabilidade, ou de que maneira é afetada pelas potências excitantes. [...] Mas quanto a isso, e em qualquer outra questão, devemos contar com os fatos; e cuidadosamente evitar a escorregadia questão a respeito das causas, como sendo, em geral, incompreensível, e como tendo sempre provado a desgraça [bane] da filosofia (Brown, 1803, p. 90).

Nesse sentido, o problema a ser colocadoé o da possibilidade de sistematizar o monismo browniano em termos fundacionistas. Se, como sugere John Neubauer, esse monismo, apesar de todas as dificuldades metodológicas que apresentava, ganhou repercussão na Alemanha pós-kantiana em função de sua tendência em "generalizar" (Neubauer, 1967, p. 379), para que essa operação se tornasse legítima era preciso reformulá-la como uma tese filosófica - algo que não parecia interessar especialmente ao próprio John Brown. Foi Andreas Röschlaub quem assumiu para si tal tarefa. Uma das principais figuras públicas do campo da medicina, Röschlaub, também professor da Universidade de 
Bamberg, havia publicado em 1798 suas Untersuchungen über Pathogenie, onde se propunha, como informa explicitamente o subtítulo da obra, a elaborar uma "explicação, fundamentação [Bearbeitung, Begründung] da teoria dos estímulos de Brown" (citado em Neubauer, 1967, p. 371).

Essa reformulação, construindo hierarquizações e distinções que não se apresentavam em seu objeto, e, especialmente, insistindo no caráter dialético da interação entre estímulos e excitabilidade, forneceu a Brown a primeira autorização de que necessitava para a entrada no domínio da filosofia idealista especulativa e romântica. O maior exemplo dessa sua nova situação reflete-se na mudança de opinião de Schelling a seu respeito. Não só, sob o efeito da leitura das Untersuchungen de Röschlaub, ele revê a posição desenvolvida anteriormente em seu Von der Weltseele, mas mesmo a inverte em Erster Entwurf eines Systems der Naturphilosophie, publicado em 1799, fazendo das pesquisas de Brown a base para muitas de suas afirmações sobre a relação entre funções orgânicas e excitabilidade. É verdade que Schelling ainda nota a insuficiência da teoria browniana em se constituir como uma terceira via sistemática, para além dos sistemas explicativos químico-fisiológicos, de um lado, e meramente dinâmicos, de outro (cf. Schelling, 1859, pp. 152-153). Mas uma nota manuscrita posterior acrescenta a observação: sobre a possibilidade de se dar como uma tal via, "o sistema [browniano] o é segundo o princípio, mas não segundo a prática [Ausführung]" (ibidem, p. 153). É curioso perceber que essa observação, bastante enviesada de Schelling, duplica a leitura feita por Kant, também de passagem, em um de seus apontamentos pessoais, escrita em data posterior à publicação do livro de Röschlaub, ou seja, após 1798. Nela, Kant nota que, se, por um lado, "Brown apresentou o conceito do sistema das forças motoras da vida no homem, que concerne ao formal [Formale], de modo impecável", por outro, quanto ao "material e prático [Materiale und Praktische]" "não se pode entrar em acordo" (Kant, 1923, p. 963) - e a referência implícita aqui é, evidentemente, o uso de excitantes como o ópio e o álcool, tais como recomendados nos Elementa, em posição diametralmente oposta à dietética moderada, ascética e iluminista da filosofia crítica.

Seja como for, a adesão de Schelling a Brown é enfática. Supõe-se que ele, após ter viajado até Bamberg, no verão de 1800, para estudar pessoalmente com Röschlaub, tenha resolvido colocar em prática sua própria visão da medicina browniana, auxiliando no tratamento de Auguste Böhmer, filha do primeiro casamento de Caroline Schlegel - o que colaborou, possivelmente, para acelerar a piora de seu estado e, finalmente, para sua morte (cf. Tsouyopoulos, 1988, p. 372). Ainda assim, mesmo após sua ruptura definitiva com Röschlaub em 1805 (cf. Neubauer, 1967, p. 65), Schelling continuou afirmando a 
centralidade das concepções de John Brown na reelaboração filosófica do conceito de força. Foram essas as credenciais necessárias para que esse último viesse, de modo consideravelmente consistente, habitar o horizonte teórico de boa parte do século XIX, mas, de modo ainda mais singular, da geração romântica - e de Novalis.

\section{II.}

No final de 1797, numa carta de Novalis a Friedrich Schlegel, aparece o mais antigo indício de seu contato com as teorias brownianas. Ali, quase telegraficamente, o primeiro testemunha ao seu amigo o efeito positivo suscitado em Lessing pela leitura dos ditirambos que esse último lhe havia enviado. Sugerindo que Schlegel havia atingido, com sua poesia, seu objeto mais próprio, Novalis faz operar uma aproximação que denuncia, já de partida, o interesse que articula as teorias médicas e físicas de sua época a um certo elogio do excesso e, ao mesmo tempo, da totalidade: "Ele [o objeto que é a poesia] é para ti o que o láudano é para Brown - um tipo de medicina universal". ${ }^{8}$ É bem provável, no entanto, que essa referência seja indireta. Acredita-se que Novalis não tenha lido o texto original dos Elementa, nem mesmo uma tradução para o alemão - duas delas já disponíveis em 1796 (cf. Tsouyopoulos, 1988, p. 64) -, mas teria apreendido as linhas gerais de seu pensamento a partir dos comentários de Röschlaub, Eschenmayer e Schelling (cf. Schulz, 2013, p. 777).

Embora retome pontos importantes da leitura e das críticas de Schelling acerca da teoria dos estímulos de Brown, as considerações médico-físicopoéticas de Novalis a seu respeito não se deixam organizar como um desenvolvimento linear, no qual poderíamos localizar um ponto de inflexão ou conversão. Em Schelling, como vimos, mesmo as reservas explicitadas nos textos posteriores a 1799 têm como objetivo exigir uma amplificação do modelo dinâmico dessa teoria, e não simplesmente recusá-la, como era o caso antes de seu contato com Röschlaub. Em Novalis, a questão é mais sinuosa. Ao longo de seus escritos, há uma sobreposição das características louváveis e reprováveis do brownianismo, o que torna seu diagnóstico um tanto mais complexo. De um lado, essas características parecem viabilizar a superação das dificuldades do idealismo especulativo e da Wissenschaftslehre de Fichte em encontrar um monismo que não fosse nem esterilmente abstrato, 
nem meramente empírico. ${ }^{9}$ Por outro, repetindo e amplificando as reservas schellingianas de Von der Weltseele, elas aparecem como um erro que conduziria ao mecanicismo e à passividade (cf. $W$ II, p. 647). Sua leitura de Brown, atestada de modo tipicamente fragmentário, está dispersa entre os textos que compõem os Vorarbeiten, de 1797, e, principalmente, o projeto inacabado de uma enciclopédia filosófica, conhecido como Allgemeine Brouillon, um pouco mais tardio. Neles, expressa-se a profunda admiração de Novalis pela hipótese dinâmica de Brown, que, aos seus olhos, poderia resultar em uma saída consistente para o dualismo kantiano, abrindo caminho para uma concepção de alma capaz de se colocar além do binarismo passividade-atividade. Nesse sentido, a filosofia da medicina novalisiana recorre à de Brown como um subsídio ao ponto central da crítica romântica à filosofia transcendental: uma retomada do conceito de vida fora das imposições normativas da arquitetônica. Astenia e estenia traduzem-se, assim, como princípios de tensionamento que manifestam uma disposição agonística do pensamento, encontrada em muitos outros lugares da obra de Novalis: na relação entre catolicismo e luteranismo, fé e amor, rei e rainha, e assim por diante. Nenhum desses elementos se opõe ao outro como passividade; como a astenia e a estenia, nenhum desses elementos é determinado ontologicamente.

A ambiguidade dessa interpretação - um problema enfrentado diretamente pelo artigo de Neubauer (1967, p. 381) - reproduz um modelo de reflexão com que os leitores mais frequentes de Novalis talvez já estejam acostumados. Sob tal modelo encontram-se suas considerações sobre Fichte, Kant e o catolicismo, por exemplo. Em cada um desses casos, os motivos pelos quais certos aspectos doutrinários ou metodológicos são recusados reaparecem, em outro contexto, e, na maior parte das vezes, em uma escrita cifrada, como motivos para uma apologia ainda mais enfática. ${ }^{10}$ Os escritos de Novalis podem ser entendidos, sob esse aspecto, como esforços cada vez mais refinados e gradualmente mais anti-intuitivos de deslegitimar a recusa do paradoxo e pervertê-la positivamente. Ou seja, não se trata simplesmente

9 Sobre esse ponto, cf. Neubauer (1967, p. 376).

10 Um notável exemplo desse protocolo de leitura novalisiano está na questão, assinalada por vários comentadores - entre eles, Manfred Frank -, da natureza da relação entre ser e consciência, explicitada nas notas tomadas por Novalis ao longo de seus estudos de Fichte. Ora essas notas parecem compreender o ser como entidade fora de toda determinação intelectual, ora como constituída somente no nível da apreensão subjetiva (ou mesmo existencial). Uma frase como "A consciência é um ser fora do ser no ser [Bewusstseyn ist ein Seyn ausser dem Seyn im Seyn]” (WII, p. 10) instancia uma disposição reflexiva que não está comprometida, em sua origem, com o caráter explicativo da filosofia, e mais faz funcionar uma recusa que uma proposição. Uma compreensão das dificuldades metodológicas criadas por essa disposição mereceria um estudo ao qual não poderia me deter aqui. Limito-me a remeter a Nassar (2010, pp. 315 e ss.), Kennedy (2008, pp. 28-40) e Frank (1990, pp. 95-100). 
de inverter os sinais com os quais, do aristotelismo ao kantismo, pensar a contradição tornou-se uma via interditada à filosofia, como se bastasse, agora, dizer, impudentemente "A = não A" - esse passo já havia sido dado no interior da filosofia de Fichte. Empolando e implodindo a intuição abissal da identificação fichtiana, Novalis afirma "A", "A = não a", "A porque não A", "A = não A porque A (ou porque não A)" etc., e isso, concomitantemente. ${ }^{11}$ Dito de outro modo, esse procedimento traduz-se como uma espécie de análise combinatória não orientada segundo princípios causais, de tal modo que, como intérprete, Novalis procura partir dos elementos conceituais mais fundamentais de um autor para, em seguida, explorar combinações entre esses elementos que não podiam ser pensadas em seu contexto original.

Afinal, como compatibilizar, no interior da posição (e da escrita) novalisiana, a afirmação de que a segurança com que Brown pretende tornar seu sistema universal é aquilo que ele teria de melhor, formando um todo, sob esse aspecto, inquestionável ( $W$ II, p. 334) com aquela desconfiança expressa quase ao mesmo tempo, que concluiria, enfim, que justamente as bases desse sistema estariam erradas? ${ }^{12}$ Talvez uma breve distância temporal ou a suposição de um perspectivismo de tipo mais sistemático, como propõe Neubauer (1967, pp. 377 e ss.), pudessem ajudar a esclarecer essa confusão. Mas essas hipóteses não resolvem, de fato, a questão da variação da recepção browniana em Novalis. Um fragmento escrito entre 1799 e 1800 parece sugerir que sua teoria médica nos permitiria pensar de modo mais adequado a natureza do corpo humano, que se mostraria mais livre e assistemático

11 Nesse sentido, Novalis duplica a posição radical de Friedrich Schlegel ao analisar as "Antinomias da razão pura" da primeira Crítica. Como se sabe, Kant considera que o problema acerca da possibilidade do conhecimento do infinito, por exemplo, não faria sentido, pois, sendo possível construir argumentos lógicos igualmente coerentes contra ou a favor dessa possibilidade, a questão se esvaziaria sob o princípio de não contradição. Para Schlegel, ao contrário, não seria o princípio de não contradição que tornaria o infinito insustentável como problema cognitivo, mas, inversamente, o infinito, por não poder ser alcançado por esse princípio, é que o esvaziaria metodologicamente (cf. Albert, 1993, pp. 826-827). Nesses termos, o caos, a incompletude, a vulgaridade, sendo caraterísticas cosmológicas, devem se manifestar epistemologicamente. Todo o intrincado e irônico texto de Schlegel "Über dir Unverstandlichkeit", publicado em 1800, no último número da revista Athenäum, é dedicado a fazer a defesa dessa vertigem gnosiológica que, simplificada brutalmente pelas versões manualescas da história, passou a denominar o contorno geral do Romantismo alemão, barrandoIhe, frequentemente, o acesso ao horizonte supostamente ascético da filosofia moderna. Cf. Schlegel (1988, Vol. 2, p. 237): "Todas as maiores verdades, de todo tipo, são completamente triviais, e, exatamente por isso, nada é mais necessário que expressá-las sempre de novo, e, onde possível, de modo cada vez mais paradoxal, para que com isso não se esqueça de que elas ainda estão ali, e de que elas nunca poderão ser propriamente enunciadas por completo".

12 Cf. WII, p. 606: "Acumulam-se, gradualmente, cada vez mais motivos que não me permitem mais vislumbrar a teoria dos estímulos brownianas sob uma luz favorável, como antes. [...] O sistema de Brown é um fugidio estimulante científico. Ele tem, aparentemente, uma forma rigorosa - mas as bases são errôneas". 
justamente porque seria aí apresentado como mais abstrato. ${ }^{13}$ Um outro, parte do mesmo conjunto, afirma justamente o oposto, ou seja, que, ao se deter no aspecto abstrato do corpo, Brown teria cedido ao excesso idealista - erro, aliás, que aparece aí como "também o grande erro de nossa política" ( $W$ II, p. 796). Entre denúncias e apologias, o grande interesse de Novalis reside na possibilidade de uma combinatória de certos elementos - especialmente os instrumentos analíticos diagnósticos - da medicina browniana. E isso, ao mesmo tempo, na medida em que essa reconfiguração paradoxal poderia revelar algo sobre a relação entre causalidade e necessidade como estrutura ontológica e gnosiológica.

Como vimos, Schelling só conseguiu se interessar por Brown após encontrar nele um caminho firme para a superação do impasse entre empirismo e solipsismo, a seu ver não resolvido satisfatoriamente nem por Kant, nem por Fichte. A mútua determinação entre estímulos externos e a propriedade interna da excitabilidade forneceria, portanto, o modelo da dialética especulativa. Estabelece-se aqui, fundamentalmente, um paralelo: o movimento dialético que Schelling procura reconhecer como conceito da medicina browniana é o mesmo que conduz sua interpretação diante dessa doutrina, que o faz levá-la à superação de suas dificuldades internas, referindo-as a uma unidade mais ampla entre afecção e espontaneidade, entre o mundo dos objetos e o do sujeito. Se, por hipótese, um paralelismo semelhante é observável em Novalis, isso se deve ao fato de que sua abordagem paradoxal/combinatória - o nível hermenêutico de sua leitura - visa a resgatar, em Brown mesmo, conceitos capazes de apontar para o paradoxo constitutivo da relação entre causalidade e efeito, exterior e interior, necessidade e contingência. E se não há o recurso de uma dialética em Novalis, se o movimento que se instaura entre todos esses polos não é o da determinação (positiva ou negativa) de uma direção ou mesmo de um círculo, mas, antes, espelha a dinâmica aberrante da própria natureza como "engenhosas inflexões e acasos, encontros e desvios" ( $W$ I, p. 223), então, qual o estatuto de uma força instauradora, ou de um conjunto de forças instauradoras, e como essa multiplicidade intensiva se relaciona com o problema da síntese epistemológica? Enfim, como se produz um corpo? É essa a questão que Novalis encontrará nas noções gerais da medicina browniana.

A topografia da medicina humoral, considerada sob esse conjunto de questões, revela sua dependência irrestrita da relação lógica, epistemológica e ontológica entre causa e efeito como paradigma de inteligibilidade. Das sentido está na doutrina browniana. Ele é, talvez, bem mais livre, assistemático, arbitrário do que acreditamos". 
desconfianças de Hipócrates acerca da loucura de Demócrito à verborragia classificatória com que o Anatomy of melancholy, de Robert Burton, quase soterrou o problema dos humores melancólicos no século XVI, o que está em jogo no centro desses debates é a mesma pressuposição de homogeneidade das patologias, de previsibilidade das terapêuticas e da moderação tendencialmente estática e inata do corpo. Ora, o que se observa no século XIX - e o Romantismo alemão está na raiz desse novo desenvolvimento - é a mudança de ênfase, que se desloca do quadro nosográfico para os sistemas de circulação e de inscrição do corpo. $\mathrm{O}$ que à época se testemunhou nessa transformação foi exatamente o que tornou possíveis as teorias físicas do magnetismo animal e do mesmerismo, a prática da hipnose de Charcot e, enfim, o inconsciente freudiano, ou seja: a intervenção de uma força, nunca totalmente apreensível logicamente e capaz de embaralhar os signos e as regras da arquitetônica da medicina dos humores. Afinal, que cartografia sintomatológica poderia ainda sustentar a aproximação entre anamnese e adivinhação e o elogio de uma força superior e invisível como matriz da vida, que Franz Mesmer defendeu em sua tese de doutorado em medicina, já em 1766 (cf. Hammoud, 1994, p. 22)? Como explicar em termos causais o corpo rígido e a afasia das histéricas? O embaraço do jovem Freud, nesse sentido, é notável: o confronto com a histeria sempre o coloca sob o risco de estar escrevendo uma ficção, de vir a afundar no ininteligível da poesia. ${ }^{14}$

Entre um horizonte epistemológico e outro, a teoria médica de Brown habita uma espécie de espaço tensionado. É certo que dela ainda se exigia uma terapêutica, mesmo que mais dinâmica. Mas o ponto mais interessante dessa teoria - especialmente para Novalis - está em seu método anamnésico. A centralidade da interação entre estímulos e excitabilidade deslocava o princípio explicativo das doenças e da saúde para seu caráter transitivo fazendo com que elas deixassem de se apoiar, assim, nos esquemas e quadros clássicos. Isso significou, para Brown, investigar como a mesma condição física poderia ser produzida não apenas por elementos diferentes, mas por elementos antitéticos. Sua grande contribuição, nesse sentido, foi aquilo que ele chamou de astenia indireta. A ideia de que a ausência de reação da excitabilidade (nas condições astênicas) poderia ser explicada pela carência de

14 O próprio Freud lembra-nos de que, na análise da histeria, não se aplica a máxima "cessante causa cessat effectus [cessando a causa, cessa o efeito]", de tal modo que o efeito se desvincula da determinação que o produzia diretamente - daí por que o principal sofrimento da histérica se define por meio do objeto fantasmagórico da lembrança: "a histérica sofre, sobretudo, de reminiscências [Reminiszenzen]" (Freud, 1952, p. 86). Além disso, muitas vezes Freud se esforçou, voluntariamente, para apagar as fronteiras entre seus estudos de caso e as narrativas de romances (cf. Mahony, 1982, p. 11). Todos os grifos são meus. 
estímulos, bem como a sua tese complementar, a de que a hipersensibilidade da excitabilidade (nas condições estênicas) se revelaria a partir de um excesso de estímulos, ainda se inscrevia na relação determinada clássica entre causa e efeito. O que torna as coisas um pouco mais complicadas é a hipótese browniana segundo a qual a ausência de reação da excitabilidade poderia ser causada também pelo excesso de estímulos - condição astênica, ou seja, de esgotamento, mas indireta, pois produzida por uma via antes insuspeita. Não se tratava mais de dizer que a doença $x$ poderia ser causada por $A$ ou $B$, mas por $A$ ou não $A$. Se Brown se esforçou, ao abordar a síntese das patologias, por lançar mão de recursos instrumentais padronizados, como escalas de intensidade, padrões de circulação etc., esses instrumentos, contudo, permanecem, sempre, aproximativos, e a dificuldade reside em reconduzir tal síntese à multiplicidade de suas possibilidades e, ali, determiná-la. A atividade do médico, assim, guarda algo de constitutivamente imponderável: os anos de estudo e experiência podem garantir-lhe, pela disciplina, um certo estado de prontidão, mas o gesto com o qual ele decide se o esgotamento é causado pela falta ou pelo excesso, por A, ou não A, é um salto único e irrepetível. Há algo de fundamentalmente artístico em seu ethos. E foi nesse ponto preciso, nessa reformulação do sentido de causa, que a medicina de Brown despertou tantos furores - a questão foi conduzida, a despeito dos interesses de seu autor, ao nível das consequências mais gerais que se disputavam entre uma filosofia da natureza e uma estética.

Visando explorar esse entrelugar, Novalis dedicou-se a traduzir o brownianismo em termos propriamente metafísicos. Antes de tudo, seria preciso redefinir, filosoficamente, a expressão "indireto". Isso é feito em um fragmento de 1798 a respeito dos fenômenos do galvanismo - uma teoria que estava bastante em voga no período romântico justamente por se ocupar com uma força instável e descontínua, ainda não completamente mensurável pelos instrumentos da época: a eletricidade orgânica. Não é por acaso que a elaboração de um novo paradigma de efetividade tenha surgido nesse âmbito. O interesse de Novalis - mas também o de Goethe, Ritter e Schelling - em pensar domínios como o galvanismo, a eletricidade, a química e a combustão, por exemplo, como matrizes de explicação para a passagem da potência ao ato revela muito sobre seus esforços para pensar, fora do esquematismo kantiano, a passagem imprevisível do múltiplo à síntese, do inorgânico ao orgânico, do nada ao ser e vice-versa. ${ }^{15}$ Seja como for, é no fragmento sobre galvanismo - ou ígneo - A alma devora o c<orpo> (e o digere?) instantaneamente - o corpo recebe a alma - (e dá-lhe a luz?) instantaneamente". 
que Novalis, ao utilizar o termo direto, acrescenta como sinônimo, entre parênteses, "(necess $<$ ário $>[$ nothw $<$ endige $>])$ ", e, analogamente, ao termo indireto faz corresponder "(aleat<ório $>$ [zufäll $<$ ige $>$ ])" ( $W$ II, p. 342). Nota-se o alcance dessa definição no trecho que se segue no mesmo fragmento, quando, à pergunta "Os efeitos [Wirckungen] do mundo externo sobre nossas almas etc. são efeitos diretos ou indiretos?", Novalis responde, peremptoriamente: "Indiretos"16 (idem). Entende-se, assim, como o conceito de astenia indireta de Brown instrumentaliza a revisão novalisiana dos esquemas explicativos tradicionais da medicina, mas, mais amplamente, da ligação entre causa e efeito. Ele mostra como o grau zero de excitabilidade pode estar vinculado tanto à falta quanto ao excesso de estímulos.

Mas, para que a interpretação combinatória de Novalis se completasse, seria necessário ainda dar um último passo. É esse o movimento que explica como Novalis formulou o conceito de estenia indireta, inexistente em Brown. Como seria de se esperar, ele surge de maneira frequentemente muito equívoca. Simplificado, pode ser compreendido como a possibilidade de um máximo de excitabilidade ser produzido por um mínimo de estímulo (cf. $W$ II, p. 362). Com isso, exatamente o único elemento que Röschlaub teria "esquecido" (cf. $W$ II, p. 562) em sua reatualização da medicina browniana seria aquele que fecharia o circuito combinatório: com a estenia indireta, enfim, pode-se combinar causa e efeito de todos os modos: ausência (ou esgotamento) de excitabilidade promovida pela falta de estímulo ou pelo seu excesso, bem como excesso de excitabilidade, igualmente provocada pela falta ou pelo excesso de estímulos. Essa indiferenciação relacional, que vem parasitar o fundamento da causalidade, funciona em Novalis como um princípio geral, em que o termo indireto viabiliza uma constante reversão do paradigma epistemológico-ontológico clássico. As complicadíssimas passagens de sua obra que tentam modular as consequências dessa revisão não formam exatamente um conjunto teórico sistemático. E isso porque, entre esquemas lacunares, gráficos indecifráveis, explicações contraditórias, o objetivo de Novalis está para além (ou aquém) de qualquer quadro argumentativo - eles visam, antes, a apontar para as possibilidades paradoxais de uma análise cuja lei não é condição, mas efeito das articulações que produz. Um fragmento escrito precisamente na época em que estudava Mineralogia na Bergakademie, de Freiburg, em 1798 (período de amplo contato com as teorias científicas

16 W II, p. 342. Formulação igualmente generalizante em $W$ II, p. 659: "Importante pergunta se a humanidade está sob o estado [Zustande] da debilidade direta ou indireta". 
então disponíveis), atesta esse esforço logicamente indecifrável - ou, do ponto de vista kantiano, inaceitável:

Assim como a doença tem sintomas da saúde, também a $s<$ aúde $>$ tem sintomas da doença.

1. Saúde direta. 2. Saúde indireta 3. Doença direta 4. Doença indireta.

Número 1 se transforma no 4, assim como o 3, no 2.

A doença indireta intermitente se transforma, no final, em direta - e também o contrário - saúde indireta constante $<$ se transforma $>$ em saúde direta. A saúde indireta se segue à doença indireta tão certamente quanto a do $<$ ença $>$ indireta $<$ se segue $>$ à saúde $(W$ II, p. 452).

Qualquer tentativa de conduzir tais observações a um modelo classificatório rigoroso estará, notavelmente, condenada ao fracasso. E, ao menos que aceitemos a saída fácil da filosofia analítica, que não enxerga em textos como esse um material digno de ser lido, limitando-se ao esquema argumentativo que ele, justamente, visa confrontar sem compactuar minimamente com ele, é preciso buscar seu sentido em outro lugar. É na consolidação universal de um procedimento de indiferenciação que busca sua legitimidade filosófica que podemos encontrá-lo. ${ }^{17}$

A inconsistência lógico-discursiva de Novalis pode ser pensada, sob esse aspecto, como um procedimento hermenêutico que não parte da evidência das distinções operadas pela reflexão - algo que, em última instância, coloca em questão a evidência da necessidade da filosofia, em seu sentido clássico, para o pensamento. A própria estrutura de diferenciação entre a condição estênica e a astênica é atingida por esse esforço de relativização: porque "estenia e astenia são sinônimos invertidos" ( $W$ II, p. 586), o espaço formado no limite das versões diretas e indiretas de cada um desses termos, inscrito no perímetro do campo combinatório novalisiano, é identificado como território da arte, ou seja, o lugar onde do arbítrio se faz a lei. Em última análise, é essa a preocupação mais enfática da escrita de Novalis: como a sintese é produzida, univocamente, a partir do arbitrio - este, por sua vez, projetando-se da estrutura do mundo para o próprio modo de pensar e para o ethos do homem romântico, seja ele poeta, filósofo ou médico, já que cada um é todos a um só tempo.

17 A diferença (que se desdobra como campo de indiferença) entre astenia e estenia e direto e indireto passa a funcionar, então, como critério que se amplia a todo campo da reflexão. Antropologicamente, Novalis fala da "astenia dos chineses" (WII, p. 405); musicalmente, pensa o que caracteriza um tom astênico e um estênico (W II, p. 541); poetologicamente, separa a poesia épica, fruto da astenia indireta, da lírica, que derivaria da astenia direta (W II, p. 361) - pode mesmo, enfim, combinar a teoria de Brown com a medicina hipocrática, chegando à distinção entre humores astênicos e estênicos ( $W$ II, pp. 545-546 e 559). 


\section{III.}

É na instauração do modelo indireto de relação entre causa e efeito que a possibilidade do idealismo mágico de Novalis se manifesta. Produzindo uma espécie de refração em sua até então pressuposta continuidade, sua visão de mundo comporta a possibilidade de qualquer causa derivar qualquer efeito: em termos médicos, isso significa dizer, por exemplo, que é possível que a vida comece astenicamente e termine estenicamente, e vice-versa (cf. $W$ II, p. 352), ou ainda que a doença seja um meio para a elevação de nossa existência ( $W$ II, p. 475). Mas essa indiferença é um princípio efetivamente universal em Novalis: são incontáveis as passagens, por exemplo, em seu Blüthenstaub, que refletem sobre as condições de passagem do incondicionado para o condicionado, do artisticamente vulgar para o nobre, do exterior para o interior (cf., respectivamente, $W$ II, pp. 227, 239 e 245) e, sempre, também, a possibilidade de sua inversão.

Desonerada da unidirecionalidade da relação causal clássica e, assim, tornada, infinitamente reversível, a realidade (sobretudo como efetividade, Wirklichkeit) apresenta-se para Novalis como aquilo que surge na interface entre o universo selvagem das multiplicidades e a decisão imediata de seu intérprete. Cabe ao homem de gênio a habilidade de revelar as conexões insuspeitas do múltiplo. Logicamente arbitrária, a síntese do modelo médico novalisiana é, entretanto, esteticamente necessária, o que faz com que Brown (nesse sentido, também, alinhado a Fichte - cf. $W$ II, p. 648) se apresente para ele como um poeta insuficiente, como alguém que havia se limitado a pensar a incompletude do movimento de síntese identitária do ponto de vista de um interesse esquemático preestabelecido. Agora, em Novalis, o médico opera indiretamente sua função e o que ele enxerga na doença é uma positividade que ele tem de configurar como obra de arte: "Toda doença é um problema musical - a terapia, uma solução musical. Quanto mais curta e, com isso, plena for a cura - maior será o talento musical do médico" ( $W$ II, p. 545). Trata-se, portanto, da possibilidade da passagem do indeterminado lógico ao determinado estético. Compreende-se, com isso, que a transformação - ou passagem - do nada ao ser deve ser lida não como transformação do vazio no pleno, mas como movimento que leva do infinitamente pleno ao sinteticamente circunscrito. Nesse sentido, a morte, por exemplo, não aparece como mera ausência. Ao contrário, uma vez que o conceito de estenia indireta havia nos informado que um máximo de excitabilidade poderia emergir de um mínimo de estímulos, morrer passa a significar atingir o sentido pleno da vida - não apenas espiritualmente, mas, o que é mais anti-intuitivo, sensivelmente. Com os místicos católicos, Novalis havia apreendido o gozo inefável da morte, o 
sentimento do infinito tornado tangível pela síntese artística. ${ }^{18} \mathrm{O}$ místico é aquele que rasura sem corpo para encontrar em seu interior o indeterminado como potência. Ao pensar o suicídio como a verdadeira tarefa filosófica (cf. $W$ II, p. 223), ao ver na morte o paradigma de uma efetividade superior (cf. $W$ II, p. 230), Novalis não está nem apontando de maneira pessimista para a desgraça constitutiva do mundo, como Baudelaire, nem querendo se tornar uma pura alma, como em alguns místicos ascetas. Seu misticismo estético expressa o caráter indireto do real, mas de modo algum o nega.

Os exemplos dados por Novalis para o conceito de estenia indireta obedecem a essa mesma economia da passagem do mínimo de ação, estendido por um longo tempo, para o máximo de efetividade, apresentado sob a forma de um sintoma agudo. São os casos da cólica ( $W$ II, p. 379), da acidez estomacal ( $W$ II, p. 603) e da gota ( $W$ II, p. 596), doenças relacionadas à ação contínua e prolongada de forças ou resíduos químicos nos órgãos e tecidos, e não, de acordo com sua apropriação de Brown, simplesmente a irrupção de uma desordem inesperada. A terapêutica imposta por essa nova ordem não pode, portanto, querer reverter um movimento que ela não domina por meio da administração de uma dinâmica de cura previsível. ${ }^{19}$ Mas talvez a consequência mais heterodoxa dessa indiferença constitutiva da relação patologia-sintoma se revele em sua contrapartida terapêutica, pois, se o médico precisa ser um artista para produzir um diagnóstico, isso quer dizer que o corpo é visado por ele como espaço de invenção, tanto da saúde quanto da doença. A essa manipulação voluntarista da materialidade física Novalis deu o nome de hipocondria. Desvinculando o termo da figura do melancólico e, portanto, do impotente, como fez uma longuíssima tradição, representada especialmente por Robert Burton, a medicina novalisiana só pôde pensar na cura como um gesto mágico mediante o qual o corpo é reconfigurado: "A hipocondria abre o caminho para o autoconhecimento - o autodomínio - a autovivificação [Selbstlebung] corporal" ( $W$ II, p. 397, grifos do autor). Formulada de outra maneira, essa hipótese seria a própria revelação de que a unidade entre corpo e alma, tão insistentemente afirmada por Novalis (cf. W II, p. 329), é uma ficção realizada pelo mago-poeta-filósofo-médico e depende, antes de tudo, de uma

18 Sobre esse ponto, comparar o fragmento de Teplitz, de 1798, que afirma a superioridade do catolicismo diante do protestantismo graças ao seu caráter "mais visível - mais unívoco [verwebter] e mais familiar" ( $W$ II, $p$. 402) - que sustenta também boa parte de Die Christenheit oder Europa - com o fragmento dos últimos anos em que afirma a filosofia de Fichte como "Cristianismo aplicado" ( $W$ II, p. 768), ou seja, como uma formulação rigorosa da vertigem das identidades.

19 Cf. WII, p. 585: "Med<icina>. Crises duradouras podem repentinamente cessar, assim como, às vezes, uma do<ença> repentina pode vir a cessar somente após muito tempo". Grifos do autor.

(Variação do tempo de convalescência - ou d<os> métodos terapêuticos do tempo [Zeitheilmethoden])". 
separação ontológica: sem ligação prévia necessária entre os dois domínios, uma combinação pode ser elaborada. ${ }^{20}$

Conduzindo todo sintoma ao domínio do Eu e sua vontade, ao arbítrio produtivo do gesto mágico, Novalis funde patologia teórica e teologia mística (cf. Schipperges, 1979, p. 48), medicina e poesia. Se "a pat<ologia $>$ browniana contém os materiais poéticos interiores - os assim chamados fil<osóficos > " ( $W$ II, p. 587), é porque ela vislumbrou a estrutura cosmológica heterodoxa em que nos encontramos. Nessa, a materialidade do corpo não representa o núcleo rígido de um universo estático, mas a potencialidade infinita de um uso estético. Corpos são, acima de tudo, uma gramática da invenção:

Como as palavras pertencem $<$ aos $>$ sintomas, então a linguagem [Sprache] é uma invenção poética - assim também todas as revelações e fenômenos são como sistemas sintomáticos - de origem [Ursprungs] poética - como poética [Pöetik] da natureza. Ao final, o fil<ósofo $>$ seria, também, somente o poeta interior $-\mathrm{e}$, assim, todo o real [Wirckliche] <seria $>$ completamente poético. Poesia [Poësie] sint $<$ ética $>-$ concomitantemente analítica do exterior e do interior) ( $W$ II, p. 587, grifos do autor).

Percebe-se, assim, em que sentido a magia, definida como "a arte de usar o mundo sensível voluntariamente [Kunst, die Sinnenwelt willkührlich zu gebrauchen]" ( $W$ II, p. 335), ${ }^{21}$ é o complemento necessário à medicina de Brown. Seu instrumento não seria mais o bisturi - assim como o artista não precisaria mais do cinzel ou o músico de suas partituras, pois operaria unicamente por meio de sua vontade absoluta, da instauração da liberdade hipocondríaca, de modo que qualquer objeto poderia fazer as vezes de uma "varinha mágica [Zauberstab]", ou seja, "um instrumento indireto" ( $W$ II, p. 343). A medicina hiperbrowniana de Novalis rompe, em sua condição última, com o princípio de razão suficiente, e instaura, assim, aquele mundo que, para Christian Wolff, ainda parecia motivo de piada:

O mundo verdadeiro se transforma em um mundo de fábula, no qual a vontade dos homens serve de razão para aquilo que acontece [...]. Ele é aquela fábula absurda que

20 É o que explica a hipótese do fragmento que diz "Devem o corpo e a alma estar, de certo modo, talvez, separados?" (WII, p. 223).

$21 \mathrm{E}$ também em $W$ II, p. 531: "O mago físico sabe como vivificar a natureza, e, voluntariamente, como tratar seu corpo"; e W II, p. 586 (Allg. Br. N. 499): « ESTILÍSTICA FISIOL<ÓGICA>. Pode-se notar no estilo se, e até que ponto, o obj<eto> [Gegenst<and>] estimula [reizt] ou não estimula o autor - e daí tirar consequências quanto à sua constituição - à sua disposição [Stimmung] ocasional etc. Estilo mais pleno - estilo mais lacunar. Estilo mais pálido - estilo mais colorido. Estilo variado - monótono. Estilo mais doentio, mais saudável - mais enfraquecido, mais energético. Métodos terapêuticos - métodos de educação [Erziehungsmethoden] $d<0\rangle$ estilo. [...] O ódio do comum leva à elegância - pois somente ela é oposta ao comum. Deve-se, enquanto homem culto, poder ser os dois, quando e como se queira. Assim, deve-se, como $\mathrm{h}<0 \mathrm{mem}>$ culto, acima de tudo, poder ser corpo e alma - estimulável e sensível à vontade". Grifos do autor. 
nos contam as velhas [...] Tens vontade de uma cereja, e eis que, ao teu comando, aparece uma cerejeira carregada de frutos maduros. À tua ordem, o fruto voa até tua boca, e, se quiseres, divide-se no ar ao meio, de modo a deixar cair o caroço e as partes murchas, para que não tenhas de cuspi-los. Pombas no espeto voam no céu e, espontaneamente, entram na boca de quem tem fome (citado em Agamben, 1993, p. 66).

\section{Referências}

AGAMBEN, G. "Bartleby o della contingenza”. In: G. Agamben, G. Deleuze. Bartleby. La formula della creazione. Macerata: Quodlibet, 1993.

ALBERT, G. "Understanding Romantic Irony: Three Essays on Friedrich Schlegel”. MLN, Vol. 108, Nr. 5, 1993.

BALDER, H.-G. "Geschichte des Deutschen Burschenschaft”. Hilden: WJK-Verlag, 2006.

BERMAN, A. "L'épreuve de l'étranger. Culture et traduction dans l'Allemagne romantique". Paris: Gallimard, 1984.

BROMAN, Th. H. "The transformation of German academic medicine 1750-1820". Cambridge: Cambridge University Press, 1996.

BROWN, J. "Elementa Medicinae". Edinburgi: Denovan, 1784.

. "The elements of Medicine". Portsmouth: William and Daniel Treadwell, 1803.

DUTCHMAN-SMITH, V. "E.T.A. Hoffmann and Alcohol. Biography, Reception and Art". London: Maney, 2009.

FOUCAULT, M. "Naissance de la clinique". Paris: PUF, 1963.

FRANK, M. "Zeitbewusstsein”. Pfullingen: Günther Neske, 1990.

FREUD, S. "Studien über Hysterie”. In: Gesammelte Werke. Bd. 1. London: Imago, 1952. HAMMOUD, S. "Mesmérisme et romantisme allemand”. Paris: L'Harmattan, 1994.

KANT, I. "Gesammelte Schriften”. Bd. XV: Anthropologie. Berlin: de Gruyter, 1923. KENNEDY, C. "Paradox, Aphorism and Desire in Novalis anda Derridai". London: Maney, 2008.

LONGRIGG, J. “Greek Rationale Medicine”. New York: Routledge, 1993.

MAHONY, P. "Freud as a writer". Madison: International University Press, 1982.

NASSAR, D. "Interpreting Novalis' 'Fichte-Studien'“. Deutsche Vierteljahrsschrift für Literaturwissenschaft Und Geistesgeschichte, Vol. 84, Nr. 3, 2010.

NEUBAUER, J. "Dr. John Brown (1735-1788) and early German Romanticism". Journal of the History of Ideas, Vol. 28, Nr. 3, 1967.

NIEWOEHNER-DESBORDES, U. "Der Brownianismus und die Göttinger Unruhen 1802, oder ein Scharlachstreit”. In: Würzburgermedizinhistorische Mitteilungen, Bd. $12,1994$.

NOVALIS. "Werke, Tagebücher und Briefe". 3 Bde. Herausgegeben von Hans-Joachim Mähl und Richard Samuel. 2. Aufl. München: Carl Hanser, 2005.

PARÉ, A. “Textes choisis”. Paris: Belles Lettres, 1953. 
SCHELLING, F. J. W. von. "Erster Entwurf eines Systems der Naturphilosophie". In: Sämmtliche Werke. Hrsg. Von Karl Schelling. Stuttgart; Augsburg: Cotta, 1859. . "Von der Weltseele." In: Werke. Bd. 1. Leipzig: F. Eckardt, 1907.

SCHLEGEL, F. "Kritische Schriften und Fragmente", 6 Bde., herausgegeben von Ernst Behler und Hans Eichner. Paderborn/München/Wien/Zürich: Ferdinand Schöningh, 1988. SCHIPPERGES, H. "Grundzüge einer theoretischen Pathologie bei Novalis". In: W. Doerr, H. Schipperges. Was ist theoretische Pathologie?. Berlin; Heidelberg; New York: Springer, 1979.

SCHULZ, G. "Kommentarteil”. In: Novalis. Werke. Herausgegeben und kommentiert von Gerhard Schulz. 5. Auf. München: C. H. Beck, 2013.

TSOUYOPOULOS, N. “The influence of John Brown's ideas in Germany”. In: Medical History, Supplement, Nr. 8, 1988. 